\title{
ANÁLISE DOS ELEMENTOS RELACIONAIS PARA CLIENTES DE TERMINAL PORTUÁRIO
}

\author{
Analysis of relational elements for port terminal's clients
}

\author{
José Alberto Carvalho dos Santos Claro ${ }^{[a]}$, \\ Sandra de Oliveira Soares Cardoso ${ }^{[b]}$, Camila Papa Lopes ${ }^{[c]}$
}

[a] Docente do Programa de Mestrado em Gestão de Negócios da Universidade Católica de Santos (UniSantos), Santos, SP - Brasil, e-mail: albertoclaro@unisantos.br

[b] Mestranda em Gestão deNegócios pela UniversidadeCatólica deSantos (UniSantos), Santos, SP-Brasil,e-mail: ssoares@rodrimar.com.br

[c] Mestranda em Gestão deNegócios pela UniversidadeCatólica deSantos (UniSantos), Santos, SP -Brasil, e-mail:camilapapa@hotmail.com

\section{Resumo}

Este artigo analisa os elementos relacionais valorizados por clientes de operações portuárias a partir de uma pesquisa de campo quantitativa em uma empresa de infraestrutura portuária e logística. Dentre os elementos analisados, destacam-se como propriedades dos relacionamentos os definidos por Gummesson (2005): colaboração; longevidade; comprometimento, dependência e importância; confiança, risco e incerteza; poder; frequência, regularidade e intensidade; adaptação; atração; proximidade e distância; formalidade, informalidade e transparência; rotinização; conteúdo; e propriedades pessoais e sociais. Desses elementos, foram avaliados quantos são valorizados pelos clientes como essenciais para o relacionamento com a empresa e quais os mais relevantes para a retenção desse relacionamento. Foi aplicado um survey com questões fechadas para 20 clientes via e-mail. Os resultados mostraram que os clientes consideram como elementos essenciais do relacionamento a formalidade, a rotinização e a atração.

Palavras-chave: Marketing de relacionamento. Operações portuárias. Lealdade.

\begin{abstract}
This article examines the relational elements valued by customers of port operations from a quantitative field research in a company of port infrastructure and logistics. Among the elements analyzed, we highlight properties of the relationships defined by Gummesson (2005): collaboration; longevity; commitment, dependency and importance; trust, risk and uncertainty; power; frequency, regularity and intensity; adaptation; attraction; closeness and distance; formality, informality and transparency; routinization; contents; and personal and social properties. The article evaluate how many of these elements are valued by customers as essential for the relationship with the company and which are most relevant to the retention of this relationship. We administered a survey with 20 questions for customers via e-mail. The results showed that customers consider as essential elements to the relationship formality, routinization and attraction.
\end{abstract}

Keywords: Relationship marketing. Port operations. Loyalty. 


\section{INTRODUÇÃO}

Este trabalho é direcionado ao estudo do marketing de relacionamento como fator de lealdade dos clientes. Dessa forma, apresenta-se uma ferramenta que pode ser aplicada para melhorar a satisfação deles, de forma que as empresas não se preocupem apenas com a participação no mercado e tenham foco na percepção do cliente, especialmente para as empresas que necessitam de ferramentas eficazes para melhorar o desempenho da prestação de serviços portuários, desenvolvendo atendimento com alta qualidade. Para tanto, devem adotar instrumentos que promovam maior comprometimento entre serviços e atendimento das necessidades, para que os clientes possam ser atendidos com satisfação e qualidade.

A teoria de marketing geralmente oferece as duas abordagens de orientação ao marketing e ao produto como perspectivas opostas; contudo, estes devem ser analisados separadamente, pois são funções centrais da empresa e sua aproximação é a principal contribuição do gerenciamento moderno de qualidade, uma das teorias que inspiraram a abordagem de 30Rs de Gummesson (2005).

Para reforçar a orientação ao marketing, é preciso mudar valores e atitudes pessoais e instalar nova forma de liderança, e o sucesso não é resultado de uma estratégia “ou/ou”, de orientação à produção e gerenciamento da qualidade interno ou orientação ao marketing e gerenciamento da qualidade externo, mas deve ser uma combinação de ambos.

Até 1980 , o foco era a qualidade na produção, sem ênfase no marketing; contudo, o recente conceito de qualidade que tem implicações para o marketing é que este fortalece o relacionamento entre gerenciamento de operações e administração de marketing. A parte externa do total quality management envolve a qualidade percebida pelo cliente, que é expressa, na teoria de marketing, em termos de necessidades, satisfação e clientes satisfeitos. Assim, mesmo com stakeholders com necessidades diferentes, deve-se questionar quem é o cliente, e isto ainda não é uma realidade nos estudos de marketing.

Desta forma, questiona-se quais são os elementos do relacionamento que os clientes adotam para definir um fornecedor nas operações portuárias e tornarem-se fiéis. O objetivo é analisar os elementos relacionais valorizados por clientes de operações portuárias a partir de uma pesquisa de campo quantitativa em um terminal de contêineres.
Foi aplicado um survey com clientes de um terminal, de forma a verificar o que eles valorizam no relacionamento com a empresa.

\section{REFERENCIAL TEÓRICO}

\section{Marketing de relacionamento}

Os consumidores estão cada vez mais exigentes em relação aos valores, e lutam arduamente pela liberdade de escolha e de fazer o que quiser, dentro dos padrões impostos pela sociedade moderna. A premissa atual é a do marketing individualizado com orientação para o cliente e não somente para o mercado. Para Peppers e Rogers (2001), empresas direcionadas para o mercado costumam desenvolver um conjunto de atividades padronizadas para atender a um grande segmento, e as direcionadas ao cliente procuram conhecer as necessidades de cada cliente antes de propor um mix de serviços.

Segundo Nickels e Wood (1999), muitas empresas atualmente estão ampliando suas atividades para além dos 4 Ps. É fácil perceber que falta um item nesse conjunto, que são as pessoas. Explicam a construção de relacionamento como "o processo de atrair e manter os clientes ao longo do tempo, mantendo contato e fornecendo serviços antes, durante e depois da venda, como parte do marketing de relacionamento". Gummesson (2004) define marketing de relacionamento como o conjunto de interações dentro da rede de relacionamentos. Para ele, "relacionamentos exigem que pelo menos duas pessoas estejam em contato. O relacionamento fundamental do marketing é aquele entre um cliente e um fornecedor". (GUMMESSON, 2005, p. 22).

Segundo Gosling e Gonçalves (2006), para criar o desejo dos consumidores é necessário avaliar algumas variáveis, como qual público pretende-se atingir, saber o que esse público espera e, dessa forma, segmentar e posicionar o produto. Deve-se atentar que a ênfase do marketing mudou na prestação de serviços. No lugar do produto, a base é o relacionamento com os clientes, para saber quais são as suas necessidades, desejos e expectativas, e surpreendêlos, tornando-os mais leais tanto à marca quanto à empresa (VAVRA, 1993; BERRY, 2001).

Propõe-se um modelo analítico do encontro de serviço. Essa abordagem tem a finalidade de analisar o valor do cliente pelo relacionamento 
estabelecido nos encontros com os gestores de serviços, pela experiência que terá e o valor percebido da qualidade do serviço pelo contato com o gestor. Os autores acreditam que o valor que o cliente atribui aos serviços é percebido no primeiro contato (FRICHOL, 2008; GOSSELIN; BAUWEN, 2006).

Conforme McKenna (1992), as estratégias de marketing tradicionais são inadequadas, pois não avaliam a tecnologia e as mudanças como elementos importantes e, principalmetne, porque o desenvolvimento e a manutenção de boas relações com os clientes nunca é sua meta. Tal argumento coaduna-se com Hoffman e Bateson (2003, p. 436),

O marketing de relacionamento dá ênfase à importância da retenção do cliente e à preocupação com a qualidade, que transcende os limites departamentais. Amplia a definição do cliente de usuário final para todos os grupos (fornecedores, funcionários, segmentos influentes etc.), que integram o processo de levar o bem ou o serviço para o mercado. Os esforços para reter todos esses tipos de clientes estão na essência do conceito do marketing de relacionamento.

Para Liu, Petruzzi e Sudharshan (2007), o relacionamento é importante nas empresas prestadoras de serviço por sua natureza intangível, o que impede que o consumidor tenha uma unidade de valor com a empresa. Após a execução do serviço, o que irá permanecer é o elo com o cliente, o que irá contribuir para que ele retorne à empresa posteriormente, além da propaganda boca a boca que realiza.

Gumesson (2004) entende que é preciso construir relacionamentos duradouros e manter clientes fiéis, e essa política deve ter início dentro das empresas. As primeiras pessoas que necessitam aprender e se comprometer com essa política são os funcionários da empresa, considerados os clientes internos. Segundo Kotler e Keller (2006), os consumidores definem uma hierarquia de valores, desejos e necessidades com base em dados empíricos, opiniões, referências obtidas por meio da propaganda de boca e experiências anteriores com produtos e serviços.

Para Kotler e Keller (2006), a hierarquia de valor para o cliente indica que o valor desejado é composto de preferências por dimensões específicas e mensuráveis - os atributos, os desempenhos dos atributos e as consequências ligadas aos objetivos da situação de uso. Os clientes avaliam o desempenho da oferta em cada uma dessas dimensões, constituindo um sentimento de satisfação pelo valor recebido. $\mathrm{O}$ paralelo estabelecido entre valor e satisfação conduz a um escopo mais amplo, cuja preocupação está em compreender o que o cliente valoriza, e não apenas verificar em que medida eles estão ou não satisfeitos.

O cliente é quem define a demanda, surgindo daí a necessidade de investir no marketing de relacionamento, pois constitui o processo contínuo de identificação e criação de novos valores com clientes individuais e o compartilhamento de seus benefícios durante uma relação de parceria duradoura, proporcionando à organização o diferencial para competir e conquistar novos clientes, solidificando a organização.

O marketing de relacionamento tem condições de oferecer às empresas uma série de vantagens importantes, tais como desenvolver a fidelidade entre os clientes, dispor de um ambiente que favoreça soluções inovadoras, estabelecer um local propício para testar novas idéias e alinhar a empresa com os clientes que valorizam o que ela tem a oferecer (GORDON, 1998, p. 23).

O marketing de relacionamento poderá oferecer à empresa condições de conhecer as necessidades e preferências de seus clientes, como verificar quais são os pontos fortes, neutros e principalmente deficientes em sua organização, ou mesmo dos seus concorrentes, podendo copiar e até melhorar e aprender com seus erros, evitando repeti-los.

\section{METODOLOGIA}

A metodologia adotada foi o estudo de caso a partir da realização de uma pesquisa de campo quantitativa, pela aplicação de um survey com questões fechadas. O estudo de caso é uma construção apropriada sob várias circunstâncias. Primeiro, ele é análogo a um experimento em que as mesmas condições o justificam, ou seja, tanto na simplicidade quanto em passos para uma construção positiva. Assim, uma razão para se adotar um estudo de caso é quando esse representar uma peça cuidadosamente testada em uma teoria bem formulada (YIN, 2005).

A empresa é um grupo que presta serviços de assessoria aduaneira, agenciamento marítimo, operação portuária, frete internacional, transporte rodoviário e 
armazenamento, além do acompanhamento de todo o processo logístico da carga até o seu destino final. Possui infraestrutura de terminais marítimos, instalações portuárias alfandegadas para movimentação de carga conteinerizada, carga geral e granel sólido, carga projeto, além de Porto Seco, no interior de São Paulo, e terminal para reparos de contêineres.

O estudo de caso ocorreu em uma unidade da empresa situada na cidade de Santos, SP, que opera com instalação portuária alfandegada. Tal unidade possui 20 clientes de relacionamento de longo prazo, e foi aplicado um survey a 16 deles, representando $80 \%$ da amostra. Segundo Malhotra (2001, p. 179), "o método survey apresenta diversas vantagens. Em primeiro lugar, sua aplicação é simples. Em segundo, os dados são confiáveis, porque as respostas são limitadas às alternativas mencionadas". Também se observa que há redução de variabilidade nesse tipo de pesquisa, que poderia ser causada pela diversidade de respondentes. No presente caso, todos fazem parte de um grupo seleto de clientes que mantêm relacionamento de mais de um ano com a empresa, portanto, segmentado e pertencente a organizações de grande porte, que utilizam a infraestrutura portuária.

Por tal critério, o método de amostragem foi não probabilístico por acessibilidade, definido por Mattar (1998) como de facilidade de acesso e disposição dos clientes em responder a pesquisa.

Para a definição dos elementos de análise do relacionamento, foram adotados os propostos por Gummesson (2005), e cada um deles foi explicado de forma que o cliente pudesse entender o significado. Em seguida, foram definidos os critérios para cada elemento, considerando-se quatro ou cinco variáveis de respostas, dependendo da complexidade deles, de forma a facilitar a identificação, pelo respondente, do significado de cada critério e, portanto, permitindo a identificação de quantos e quais elementos possuem maior importância no relacionamento, conforme se verifica a seguir.

\section{Colaboração}

Neste item (Quadro 1) avalia-se a colaboração entre fornecedores, consumidores, competidores, consultores, governos e outros, com a finalidade de analisá-la em relação ao grau de competitividade. O relacionamento harmonioso depende de alta colaboração e baixa competitividade.

\begin{tabular}{|l|l|l|l|l|l|}
\hline Colaboração & Não existe & Ruim & Regular & Bom & Excelente \\
\hline $\begin{array}{l}\text { Colaboração entre empresa e clientes no } \\
\text { fornecimento de serviços }\end{array}$ & & & & & \\
\hline
\end{tabular}

QUADRO 1 - Colaboração entre fornecedores, consumidores, competidores, consultores, governos e outros

\section{Longevidade}

Éanalisada a longa duração do relacionamento, considerando o tempo gasto na sua construção(Quadro 2).

\begin{tabular}{|l|l|l|l|}
\hline Longevidade & De 1 a 5 anos & De 5 a 10 anos & Mais de 10 anos \\
\hline $\begin{array}{l}\text { Tempo de duração do } \\
\text { relacionamento com a empresa }\end{array}$ & & & \\
\hline
\end{tabular}

QUADRO 2 - Longevidade do relacionamento 


\section{Comprometimento, dependência e importância}

Dependendo da importância do relacionamento, há dependência entre as partes e estas estão comprometidas para fazê-la funcionar. Existem três níveis de dependência e comprometimento: no nível 1, a atração é o preço; no nível 2, a relação se aprofunda e há comunicação; no nível 3, há dimensão estrutural, com união de recursos e alto comprometimento (Quadro 3).

\begin{tabular}{|l|l|l|l|}
\hline $\begin{array}{l}\text { Comprometimento, } \\
\text { dependência e importância }\end{array}$ & $\begin{array}{l}\text { Nível 1 (Muita } \\
\text { importância) }\end{array}$ & $\begin{array}{l}\text { Nível 2 (Pouca } \\
\text { importância) }\end{array}$ & $\begin{array}{l}\text { Nível 3 (Nenhuma } \\
\text { importância) }\end{array}$ \\
\hline Nível de comprometimento e dependência & & & \\
\hline
\end{tabular}

QUADRO 3 - Comprometimento, dependência e importância

\section{Confiança, risco e incerteza}

O sucesso da colaboração e o comprometimento dependem da confiança na empresa e na prestação de serviços. Quanto maior a confiança, menor o risco e a incerteza, e o relacionamento tende a se aprofundar (Quadro 4).

\begin{tabular}{|l|l|l|l|l|}
\hline $\begin{array}{l}\text { Confiança, risco } \\
\text { e incerteza }\end{array}$ & $\begin{array}{l}\text { Não existe confiança } \\
\text { neste mercado }\end{array}$ & $\begin{array}{l}\text { Baixa } \\
\text { confiança }\end{array}$ & $\begin{array}{l}\text { Média } \\
\text { confiança }\end{array}$ & $\begin{array}{l}\text { Alta } \\
\text { confiança }\end{array}$ \\
\hline Grau de confiança & & & & \\
\hline
\end{tabular}

QUADRO 4 - Confiança, risco e incerteza

\section{Poder}

O poder no relacionamento dificilmente é simétrico, ou seja, raramente cada parte o exerce na mesma proporção. O excesso de poder por parte da empresa compromete o relacionamento (Quadro 5).

\begin{tabular}{|l|l|l|l|}
\hline Poder & $\begin{array}{l}\text { A empresa detém } \\
\text { poder de mercado }\end{array}$ & $\begin{array}{l}\text { Existe equilíbrio entre poder de oferta } \\
\text { da empresa e demanda dos clientes }\end{array}$ & $\begin{array}{l}\text { O cliente detém } \\
\text { poder de demanda }\end{array}$ \\
\hline Relação de poder & & & \\
\hline
\end{tabular}

QUADRO 5 - Poder no relacionamento

\section{Frequência, regularidade e intensidade}

Analisando o contrato firmado entre cliente e empresa, observa-se a frequência de utilização do serviço, a regularidade com que a empresa presta um serviço e a intensidade, representada pela lealdade do cliente pela empresa (Quadro 6). 


\begin{tabular}{|l|l|l|l|}
\hline $\begin{array}{l}\text { Frequência, } \\
\text { regularidade e } \\
\text { intensidade }\end{array}$ & $\begin{array}{l}\text { Utiliza serviços } \\
\text { logísticos de } \\
\text { diversas empresas }\end{array}$ & $\begin{array}{l}\text { Utiliza serviços logísticos da } \\
\text { outras empresas mas a maior } \\
\text { parte da empresa atual }\end{array}$ & $\begin{array}{l}\text { Somente utiliza os } \\
\text { serviços de empresa }\end{array}$ \\
\hline $\begin{array}{l}\text { Utilização dos } \\
\text { serviços logísticos }\end{array}$ & & & \\
\hline
\end{tabular}

QUADRO 6 - Frequência, regularidade e intensidade

\section{Adaptação}

A adaptação dos clientes refere-se à sua adequação aos sistemas e procedimentos impostos pela empresa prestadora de serviços ou vice-versa (Quadro 7).

\begin{tabular}{|l|l|l|l|}
\hline Adaptação & $\begin{array}{l}\text { Não foram necessárias } \\
\text { adaptações }\end{array}$ & $\begin{array}{l}\text { O cliente deve } \\
\text { adaptar-se à empresa }\end{array}$ & $\begin{array}{l}\text { A empresa } \\
\text { adapta-se ao cliente }\end{array}$ \\
\hline $\begin{array}{l}\text { Adaptação de sistemas } \\
\text { e procedimentos }\end{array}$ & & & \\
\hline
\end{tabular}

QUADRO 7 - Adaptação dos clientes aos sistemas e procedimentos da empresa

\section{Atração}

A atração é representada pela combinação de motivos racionais e financeiros e também de fatores psicológicos, tais como a atratividade da empresa e da marca. A atração pode ser avaliada pelos motivos que levam à criação de relacionamento, tais como custo dos serviços, imagem da empresa, entre outros (Quadro 8).

\begin{tabular}{|l|l|l|l|l|}
\hline Atração & Custo baixo & Tipos de serviços & $\begin{array}{l}\text { Imagem e marca } \\
\text { da empresa }\end{array}$ & Outro. Qual? \\
\hline $\begin{array}{l}\text { Motivo pelo qual mantém } \\
\text { relacionamento com a empresa }\end{array}$ & & & & \\
\hline
\end{tabular}

QUADRO 8 - Atração

\section{Proximidade e distância}

A proximidade entre empresas e consumidores pode ser analisada de diversas formas. Ela fortalece a sensação de segurança, representada por entendimentos tácitos entre partes, que nem sempre são definidos em contratos (Quadro 9).

\begin{tabular}{|l|l|l|l|}
\hline Proximidade & $\begin{array}{l}\text { Todos os aspectos da } \\
\text { prestação de serviços } \\
\text { definidos em contrato }\end{array}$ & $\begin{array}{l}\text { Detalhes e benefícios no dia a } \\
\text { dia que não estão no contrato }\end{array}$ & Não existe contrato \\
\hline $\begin{array}{l}\text { Como é o } \\
\text { relacionamento }\end{array}$ & & & \\
\hline
\end{tabular}

QUADRO 9 - Proximidade e distância 


\section{Formalidade, informalidade e transparência}

As relações comerciais tendem a ser mais informais e as regras nem sempre estão estabelecidas em contratos formais e regulamentados. Relacionamentos importantes e duradouros são criados com informalidade, mas é preciso haver transparência como forma de confiança (Quadro 10).

\begin{tabular}{|l|l|l|l|}
\hline $\begin{array}{l}\text { Formalidade, informalidade e } \\
\text { transparência }\end{array}$ & $\begin{array}{l}\text { Reuniões informais } \\
\text { em lugares públicos }\end{array}$ & $\begin{array}{l}\text { Reuniões somente } \\
\text { na empresa, com } \\
\text { regras rígidas }\end{array}$ & $\begin{array}{l}\text { Equilíbrio entre } \\
\text { informalidade e } \\
\text { formalidade }\end{array}$ \\
\hline $\begin{array}{l}\text { Formato de relacionamento e } \\
\text { tomadas de decisões }\end{array}$ & & \\
\hline
\end{tabular}

QUADRO 10 - Formalidade, informalidade e transparência

\section{Rotinização}

Os procedimentos rotineiros são considerados necessários para manter a eficiência na prestação de serviços. No relacionamento B2B, as rotinas são estabelecidas para entregas a partir de procedimentos padronizados. A tecnologia é adotada como meio para troca de recursos por apresentar diminuição de custos e agilizar processos, sendo um diferencial no relacionamento (Quadro 11).

\begin{tabular}{|l|l|l|l|}
\hline Rotinização & $\begin{array}{l}\text { Procedimentos e } \\
\text { comunicação são } \\
\text { padronizados }\end{array}$ & $\begin{array}{l}\text { Existe rotina nos } \\
\text { processos e na } \\
\text { prestação de serviços }\end{array}$ & $\begin{array}{l}\text { Não existe rotina ou } \\
\text { padronização nos processos } \\
\text { e na prestação de serviços }\end{array}$ \\
\hline $\begin{array}{l}\text { Procedimentos e } \\
\text { comunicação nos } \\
\text { processos }\end{array}$ & & & \\
\hline
\end{tabular}

QUADRO 11 - Procedimentos rotineiros

\section{Conteúdo}

O conteúdo é representado pela troca econômica em que um lado fornece bens e serviços e outro, o pagamento. Essa troca é expressa em termos de conhecimento e informação e propicia a coordenação e utilização de recursos para a fabricação ou distribuição, de forma a criar valor conjunto (Quadro 12).

\begin{tabular}{|l|l|l|l|}
\hline Conteúdo & $\begin{array}{l}\text { Existe parceria ou aliança } \\
\text { entre empresa e cliente }\end{array}$ & $\begin{array}{l}\text { Há troca de conhecimentos } \\
\text { e informação }\end{array}$ & $\begin{array}{l}\text { Não há troca } \\
\text { nem parceria }\end{array}$ \\
\hline $\begin{array}{l}\text { Interação e } \\
\text { conhecimento entre } \\
\text { empresa e cliente }\end{array}$ & & & \\
\hline
\end{tabular}

QUADRO 12 - Conteúdo 
Segundo Gummesson (2005), existem outras propriedades pessoais e sociais que avaliam a construção de relacionamento, algo que nem sempre é simples de se definir. $O$ autor sugere que essa análise não se encerre em si e afirma que, embora ela possa contribuir para a avaliação do relacionamento, seu início, continuidade e término, não deve ser tomada como a única base para decisões em marketing, planejamento e execução, uma vez que mais de uma propriedade pode ser determinante para a criação e manutenção do relacionamento com o cliente.

Para definir quantos e quais elementos são os mais importantes, foi atribuída uma nota a cada elemento, além de uma justificativa para a opção do cliente. A variação de notas foi de 0 a 3 , adotando a escala de Likert de 5 pontos: 0 - não possui importância, 1 - possui pouca importância, 2 - possui importância razoável, 3 - possui grande importância, e 4 - é essencial.

\section{ANÁLISE E INTERPRETAÇÃO DOS RESULTADOS}

A aplicação de survey mostrou como resultado a percepção dos clientes de uma empresa de operações portuárias e logística, na unidade de Santos, e observou-se que esses apreciam todos os elementos propostos por Gummesson (2005), já que não há notas 0 (zero). Conforme apresenta a Figura 1, os critérios mais importantes são formalidade, rotinização e atração, considerando as notas 4 (essenciais).

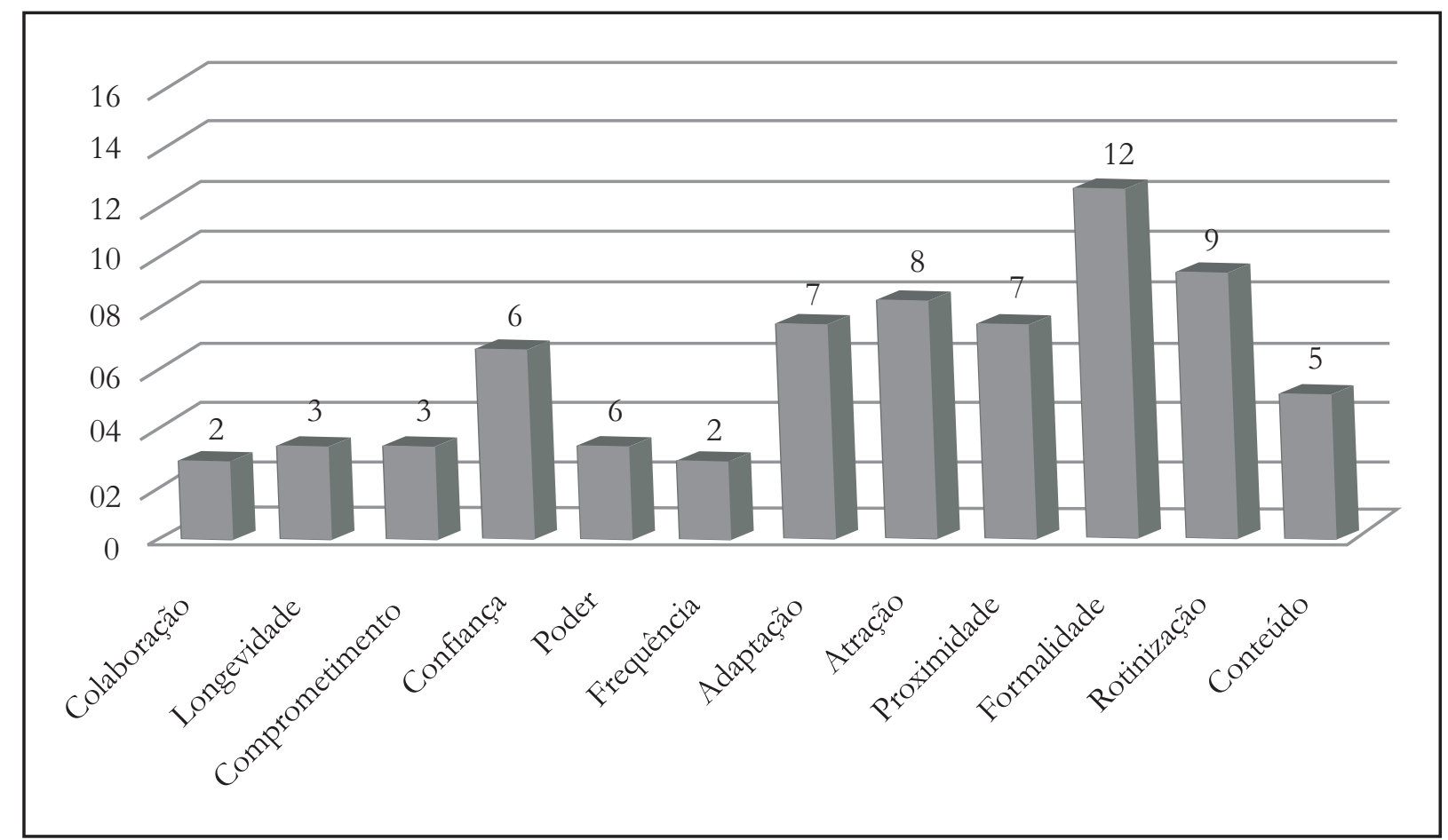

FIGURA 1 - Elementos essenciais para o relacionamento cliente-empresa Fonte: CLARO; CARDOSO; LOPES, 2009.

A justificativa para o resultado da formalidade é que a empresa busca equilíbrio entre formalidade e informalidade. Segundo $75 \%$, existem procedimentos padrão adotados pela empresa, porém, conforme a necessidade do cliente, há jogo de cintura na organização, criando-se diferenciais para cada cliente, ou seja, personalização do serviço e atendimento um a um, o que satisfaz e atende às necessidades. Já para 15\% existe excesso de formalidade em reuniões e procedimentos, o que pode prejudicar as operações quando houver necessidade de adaptações no serviço. 
Em relação à rotinização, 56\% entendem que há rotina sem padronização na empresa, o que facilita o atendimento ao cliente e o fornecimento de serviços no momento em que precisam. Trinta por cento alegam padronização dos serviços e 14\% entendem que não há regras nem padronização.

Quanto ao critério atração, $50 \%$ consideram que o atrativo é o tipo e a variedade de serviços oferecidos pela empresa, 31\% consideram que o custo baixo é o diferencial e 13\% atribuem isso à imagem da empresa no mercado.

A adaptação foi identificada por $44 \%$ dos clientes como critério importante, pois a empresa adapta seus serviços conforme a necessidade deles; $37 \%$, contudo, entendem que eles devem se adaptar a empresa, por causa da documentação no processo aduaneiro, e 19\% acreditam que não é necessário adaptação, pois há compatibilidade entre sistemas da empresa e dos clientes.

A proximidade foi considerada por $44 \%$ dos respondentes, pois os aspectos da prestação de serviços são definidos em contrato, o que garante segurança aos clientes. Vinte e cinco por cento alegam que não há contrato na prestação de serviços e $21 \%$ constatam que há contrato, mas alguns benefícios que a empresa oferece não estão nele discriminados.

A confiançaé entendida por $37 \%$ da amostra como essencial na manutenção do relacionamento, porém 44\% consideram que há média confiança na empresa, e, por este motivo, estes clientes não são totalmenteleais, utilizando serviços de outras empresas concomitantemente. Dezenove por cento entendem que não há confiança pelo tipo de serviço oferecido, pois o mercado portuário é complexo e, em muitos casos, várias empresas são necessárias para completar uma operação, ou mesmo o custo pode variar entre empresas, fazendo com que o cliente busque um serviço em uma empresa e outro serviço em outra.

O conteúdo é um critério importante na visão de $31 \%$, pois há parceria e aliança entre empresa e cliente, mas na visão de $50 \%$ há troca de conhecimentos e informação, porém, sem alianças, e 19\% consideram que não há troca e isto prejudica o relacionamento e a fidelidade.

Longevidade é considerada o elemento menos importante por somente 19\% dos respondentes, que justificam manter relacionamento com a empresa há mais de dez anos e isto lhes confere certos benefícios na aquisição de serviços. Porém, $50 \%$ mantêm relacionamento de um a cinco anos, considerando que o tempo de relacionamento não é tão importante para a prestação de serviços, mas a confiança. Trinta e um por cento sustentam relacionamento de cinco a dez anos, e também negam que o tempo de relacionamento seja determinante para a qualidade dos serviços ou manutenção de relacionamento.

O comprometimento é tido por $19 \%$ como nível 3 (grande importância), pois a prestação de serviços no tempo que o cliente necessita ou deseja somente pode ser executada pelo processo que a empresa adota, e, se não há comprometimento, o custo do serviço torna-se elevado e nem sempre é executado no tempo exigido. Já para $43 \%$ é tido como nível 2 (pouca importância no relacionamento), uma vez que o serviço logístico e portuário pouco depende do comprometimento da empresa e demanda outros elementos que nem sempre podem ser mensurados ou controlados, tais como o tempo. Trinta e oito por cento coadunam-se com tal justificativa e consideram que, pela falta de controle de fatores externos à empresa, as operações portuárias possuem nível 1 (nenhuma importância) em relação ao comprometimento, como elemento do relacionamento neste setor.

O poder é um critério importante para 19\% da amostra, pelo fato de o cliente deter o poder da demanda - ou seja, se ele não é atendido conforme espera, procurará outra empresa, e tal relação de poder faz com que as companhias lutem pela criação de relacionamento. $\mathrm{Na}$ visão de $81 \%$, contudo, há controle entre oferta e demanda em relação à execução de serviços que outras empresas não oferecem, ou mesmo que não tenham tecnologia ou qualidade suficientes ofertar.

A colaboração entre a empresa e os clientes para o fornecimento de serviços é excelente na visão de $13 \%$, porém, para $44 \%$ é boa e para $26 \%$ é regular, sendo que esta colaboração é entendida como troca de informações e busca de padronização de documentos para facilitar o processo aduaneiro.

A frequência, assim como a colaboração, foi um dos critérios menos valorizados pelos clientes. Treze por cento consideram que este elemento é importante, pois são clientes leais à empresa e só utilizam serviços desta. Entretanto, 44\% utilizam em maior quantidade os serviços da empresa pesquisada, mas também contratam outras empresas, e 33\% contratam serviços de diversas empresas, sem lealdade a nenhuma, conforme sua necessidade. 


\section{CONSIDERAÇÕES FINAIS}

Os resultados mostraram que, na prestação de serviços portuários e de logística, pela realidade um pouco diferenciada e pela influência de fatores externos, tais como modais de transporte, processos de operação, documentação e sistemas, os clientes valorizam elementos de relacionamento como medida de qualidade e satisfação em relação ao que necessitam e obtêm. Dessa forma, entende-se que o relacionamento é um critério importante para a decisão de contratar serviços portuários e logísticos.

Na pesquisa de campo, foram identificados como elementos mais importantes do relacionamento a formalidade, a rotinização e a atração, que compõem a base da confiança do cliente, pela definição de critérios (regras) para a oferta de serviços, pela gama de serviços oferecidos e pela rotina de processos, informações e variáveis incluídas.

Com este artigo, observou-se que cada segmento de negócios possui uma realidade em relação ao tipo de serviço que oferece, que irá definir a forma de relacionamento a ser criado, assim comoidentificados os elementos que devem fazerparte deste relacionamento. Assim, sugere-se a realização de estudos aprofundados sobre a realidade portuária, as necessidades dos vários atores envolvidos, a demanda e a oferta, como base para criar ou direcionar a infraestrutura de apoio.

\section{REFERÊNCIAS}

BERRY, L. Descobrindo a essência do serviço. Rio de Janeiro: Qualitymark, 2001.

FRICHOL,M.CRMas a strategic differentiator. Customer Relathionship Management, year 12, v. 1, p. 15, 2008.

GORDON, I. Marketing de relacionamento: estratégias, técnicas e tecnologias para conquistar clientes e mantê-los para sempre. São Paulo: Littera Mundi, 1998.

GOSLING, M.; GONÇALVES, C. A.; DINIZ, L. C. O. Análise experimental de estratégias de relacionamento no ensino privado: um estudo multigrupos. In: ENCONTRO NACIONALDA ASSOCIAÇÃONACIONALDEPÓSGRADUAÇÃO E PESQUISA EM ADMINISTRAÇÃO, 30., 2006. Salvador. Anais... Salvador: EnAnpad, 2006.

GOSSELIN, D. P.; BAUWEN, G. A. Strategic account management: customer value creation through customer alignment. Journal of Business \& Industrial Marketing, v. 21, n. 6, p. 376-385, 2006.
GUMMESSON, E. Return on relationships (ROR): the value of relationship marketing and CRM in businessto-business context. Journal of Business \& Industrial Marketing, v. 19, n. 2, p. 136-48, 2004.

Marketing de relacionamento total. 2. ed. Porto Alegre: Bookman, 2005.

HOFFMAN, D. K.; BATESON, J. E. G. Princípios de marketing de serviços: conceitos, estratégias e casos. São Paulo: Pioneira Thomson Learning, 2003.

KOTLER, P.; KELLER, K. L. Administração de Marketing. 12. ed. São Paulo: Pearson, 2006.

LIU, B. S-C.; PETRUZZI, N. C.; SUDHARSHAN, D. A service effort allocation model for assessing customer lifetime value in service marketing. Journal of Services Marketing, v. 21, n. 1, p. 24-35, 2007.

MALHOTRA, N. Pesquisa de marketing: uma orientação aplicada. 3. ed. Porto Alegre: Bookman, 2001.

MATTAR, F. N. Pesquisa de marketing. São Paulo: Atlas, 1998.

McKENNA, R. Marketing de relacionamento: estratégias bem-sucedidas para a era do cliente. Rio de Janeiro: Campus, 1992.

NICKELS, W. G.; WOOD, M. B. Marketing: relacionamentos, qualidade, valor. Rio de Janeiro: LTC, 1999.

PEPPERS, D.; ROGERS, M. Marketing um a um, marketing individualizado na era do cliente. 2. ed. Rio de Janeiro: Campus, 2001.

VAVRA, T. G. Marketing de relacionamento: aftermarketing. São Paulo: Atlas, 1993.

YIN, R. K. Estudo de caso: planejamento e método. 3. ed. Porto Alegre: Bookman: 2005.

Recebido: 06/05/2009

Received: 05/06/2009

Aprovado: 12/11/2009

Approved: 11/12/2009

Revisado:10/01/2010

Reviewed: 01/19/2010 